\title{
The dietary management of diabetes in adults
}

By Anthony R. Leeds, Department of Nutrition, Queen Elizabeth College, London W8 and Department of Endocrinology and General Medicine, Central Middlesex Hospital, London NWIo

Since the dietary management of diabetes is a subject which has evolved and is still evolving in response to physiological and pathological research it readily lends itself to a chronological review.

\section{The pre-insulin era}

References to what was probably diabetes mellitus are found as early as c. $155^{2} \mathrm{BC}$ in the Ebers papyrus, where a prescription of wheat grains, grapes, honey and berries is given for the 'too great emptying of urine'. Aretaeus Cappadox (c. AD 150-200), who applied the name diabetes and gave a full account of the condition in which 'the flesh and bones melted down into urine', prescribed cereals, fruits and sweet wine (Wood \& Bierman, 1972). Early Greek physicians were almost certainly aware of the sweet urine of 'diabetic' patients and the Persian physician Avicenna noted this in his writings of a thousand years ago. However, the rediscovery of this diagnostic aid is attributed to Thomas Willis, the seventeenth century physician who described the urine as 'wondrously sweet as if imbued with honey' (Marwood, 1975). By way of dietary management he described an undernutrition cure. In his Practice of Physick the dietary management of a diabetic patient is described: 'His diet was only of milk which he took sometimes raw, and diluted either with distilled or barley water, and sometimes boiled with white bread, or barley, several times a day.' (Willis, I684). A reduction of energy intake had clearly been effective. One hundred years later Matthew Dobson, a physician of Liverpool, demonstrated the presence of sugar in the urine and tried to overcome this waste of sugar by giving large amounts of sugar and honey by mouth. This treatment was not continued for more than a short period (Cammidge, 1920a).

\section{Table I. Fohn Rollo's (1797) diet for Captain David Meredith}

Breakfast: I $\frac{1}{2}$ pints milk and $\frac{1}{2}$ pint lime water, mixed together Bread and butter

Noon: Plain blood pudding, blood and suet only

Dinner: Game or old meats

Fat and rancid old meats 'as fat as the stomach may bear'

Supper: As breakfast

The credit for being first with a systematic diet for the treatment of diabetes goes to John Rollo, surgeon-general in the Royal Artillery of the British Army. In 
I 797 he published his 'account of two cases of the diabetes mellitus' (Plate I). His treatment was based on a theory that diabetes was a disease of the stomach and that it might be cured by 'diminishing the increased activity' of that organ (Rollo, 1797). The principal feature of his diet was the exclusion of vegetable substances (except for a small amount of wheat flour) and the prescription (Table I) was first applied to a Captain David Meredith. This type of diet continued to be applied in the early nineteenth century. In 1860 , Pile of Pennsylvania emphasized the importance of restricting the diet to animal food alone but Bouchardat in France tried to make the diet more acceptable by including well-boiled vegetables (Wood \& Bierman, 1972). Bouchardat also noted the reduction of glycosuria in his diabetics during the food shortages of the siege of Paris in 1871. Afterwards he stressed the importance of eating as little as possible and introduced intermittent fasting. When patients deteriorated opium was administered to 'slow down bodily function' and to it was initially attributed the many deaths in coma which occurred. It was, however, recognized that coma could occur without the use of narcotics and that coma was more likely to occur the more completely carbohydrate was excluded from the diet, so attempts were made to provide carbohydrate in a form which would prevent coma but not increase glycosuria. Towards the end of the nineteenth century special diets (the 'rice cure', the 'oatmeal cure', the 'potato cure', and the 'legume cure') had short-lived periods of popularity and were thought to work because they represented a mild form of starvation (Cammidge, 1920b), but they also represented a challenge to traditional thinking since they contained larger proportions of carbohydrate. Analysis of the porridge diet using modern values (Paul \& Southgate, 1978) indicates that on 'porridge' days the patient received $77 \mathrm{~g}$ carbohydrate, $3^{2} \mathrm{~g}$ protein and $3 \mathrm{I} \mathrm{g}$ fat $(2900 \mathrm{~kJ})$. He also received approximately twice as much total dietary fibre as he would receive in a normal diet ( $14 \mathrm{~g}$ with $2900 \mathrm{~kJ})$.

\section{The insulin era}

When insulin was introduced it was used merely as an adjunct to F. M. Allen's diet which was based on work showing that the restriction of total energy input prevented the development of diabetes in partially-pancreatectomized dogs. Such animals would develop clinical diabetes even when treated with a lowcarbohydrate, high-fat diet if total energy input was not restricted. In the 1920 s the patients were starved, usually for $3-5 \mathrm{~d}$, occasionally for $10 \mathrm{~d}$, 'to get rid' of the glycosuria. Sometimes coma interrupted this process and was 'relieved by giving food'. The patients were then given diets consisting of progressively increasing amounts of different foods in order to ascertain how much they were able to tolerate without glycosuria or marked ketosis (Maclean, 1927). Insulin was then introduced if necessary and in such cases carbohydrates were actually restricted more severely, only $4-9.5 \%$ of the energy being from carbohydrates and $\mathbf{7 2}-\mathbf{7 8 . 5 \%}$ from fat. In such diets bread does not feature as a major item and it is of interest that for patients 'occasionally requiring a substitute' bran biscuits were recommended. Each biscuit contained $9 \mathrm{~g}$ wheat bran and $7 \mathrm{~g}$ Agar agar and was 
Ex Lebris 7 freitit: ina

AN ACCOUNT OF

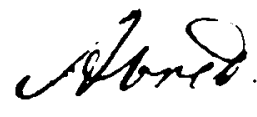

h. 1999

TWO CASES

. 113,11

OF THE

DIABETES MELLITUS:

WITH REMARKS,

AS THEY AROSE DURING THE

PROGRESS OF THE CURE.

To which are added,

A GENERAL VIEW OF

THE NATURE OF THE DISEASE

AND ITS APPROPRIATE TREATMENT,

Including Obfervations on fome Difeafes depending on

STOMACH AFFECTION;

THE COMDA DETALL OF

Received on the Subject fince the Difperfion of the Notes on the FIRST CASE.

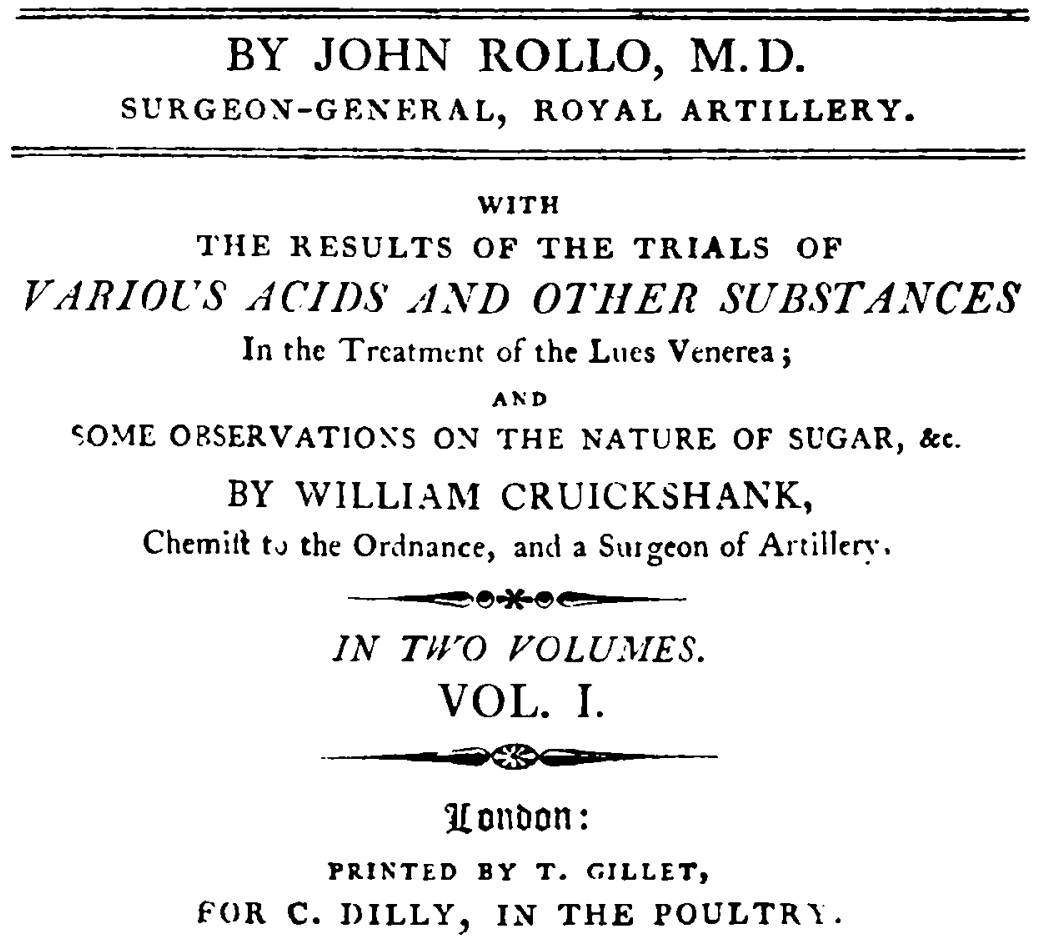

MDCCXCVIT.

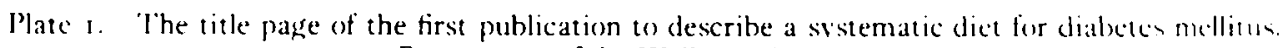
By courtesy of the Wellome Trusters.

(facins" page 366) 
always taken with a meal. In the light of recent information one might be allowed to speculate that the combination of wheat bran and Agar agar, a viscous nondigestible polysaccharide, may have had a therapeutic effect in its own right. In the 1920 bread substitutes were also made from gluten flour and soya-bean flour (Cammidge, I920c). Two of the problems related to the high-fat intake were appreciated, i.e. the increased formation of ketone bodies and the high energy value of fat which tended to undermine the principle of limiting total energy intake (Graham, 1923).

As the use of insulin became more widespread it began to be employed in conjunction with diets containing larger and larger amounts of carbohydrate (Himsworth, 1934). It had been assumed that the more carbohydrate was given the more insulin would be needed, but this was not so as insulin requirement often remained unchanged. Writing in 1929 Richardson reported details of nine cases in which changing the diet to one with a greater percentage of carbohydrate had resulted in no increase of insulin requirement and an improvement of the patients' wellbeing (Richardson, 1929). The object of changing the diets had been to increase patient compliance with dietary instructions, and the dietary changes made mostly involved increasing daily carbohydrate intake from approximately $50 \mathrm{~g}$ to over $100 \mathrm{~g}$ and reducing fat intake from roo- $150 \mathrm{~g}$ to between $5^{\circ}$ and $77 \mathrm{~g}$. Most of the patients were not overweight but Richardson (1929) noted that it was easier to cause glycosuria in the overweight diabetic when high-carbohydrate diets were given. A few years later Himsworth carried out experiments in which he gave normal volunteers high-carbohydrate or high-fat diets and showed that glucose tolerance improved after the high-carbohydrate diet (Himsworth, 1934). This effect he concluded was due to 'the organism's increased susceptibility to its own insulin'. When reviewing the diet therapy of diabetes in 1973, West recalls his surprise when in the 1950 se came to write up his success with a highcarbohydrate rice diet and discovered that the effects of 'high'-carbohydrate diets had been discovered and reported several times, but these discoveries had not greatly affected management in most centres (West, 1973). But was this really so? It is of interest to note that the high-carbohydrate diets of Richardson (1929) and Himsworth (1934) were high relative to the diets used previously but still only brought carbohydrate levels up to $30-45 \%$ of the energy. A survey of management reported in 1953 (Walker, 1953) showed that while one in every four diabetic clinics in the United Kingdom was using diets in which carbohydrate contributed only $20 \%$ of the energy, thirty-six of the eighty clinics used diets in which $32-48 \%$ of the energy was from carbohydrate. Clearly while there were variations in approach the reports of the beneficial effects of high-carbohydrate diets (Sansum et al. 1926; Richardson, 1929) and the work of Himsworth (1934) must have had some effect on raising carbohydrate rations.

Workers in Asia in the 1950 os were using diets with much higher carbohydrate content than those used in the West, reflecting the higher carbohydrate content of the diet of ordinary Asian people. Considering the results of these and other studies and bearing in mind the deleterious effects of saturated fat the Expert Committee 
on Food and Nutrition of the American Diabetes Association (ADA) decided in 1971 to recommend more generous amounts of carbohydrate than had been previously prescribed (Bierman et al. 197I). Despite the availability of this information, in 1973 most clinics in Great Britain were still recommending a low (46-50\% of the energy)-carbohydrate diet for both 'maturity-onset' and insulinrequiring disease (Truswell et al. 1975). Since the beginning of the 1970 s a number of studies have shown that the use of higher-carbohydrate diets may be beneficial. Kiehm et al. (1976) reported the effect of feeding a diet containing $75 \%$ of the energy as carbohydrate compared with the standard ADA diet containing $43 \%$ of the energy as carbohydrate. Eight of the thirteen patients were receiving insulin and five received sulphonylureas while on the ADA diet. After 2 weeks on the highcarbohydrate diet no patients required sulphonylureas, insulin was stopped or the dose reduced in five patients, and fasting plasma glucose and serum cholesterol levels were lower. Raising the carbohydrate content of the diet increased the crude fibre intake from 5 to $14 \mathrm{~g} / \mathrm{d}$ (unfortunately total dietary fibre values were not given). By contrast Weinsier et al. (1974) had shown that a high $(60 \%$ of the energy) compared with a low-carbohydrate diet ( $40 \%$ of the energy) had not altered control of diabetes and insulin secretory capacity in eighteen patients not dependent on insulin. Anderson has suggested that the amount of plant fibre in the diets used by his group was responsible for the improved diabetic control (Anderson \& Chen, 1979).

The most recent paper on this subject is that of Simpson et al. (1979) in which is described the treatment of fourteen established 'maturity-onset' diabetics with a high-carbohydrate ( $60 \%$ of the energy), high-fibre, modified-fat diet for 6 weeks compared with the usual 'low' ( $34 \%$ of the energy)-carbohydrate diet. Basal plasma glucose concentrations fell and the percentage of glycosylated haemoglobin (an indication of integrated glucose levels over the preceding study period) was reduced after the 6-week high-carbohydrate diet. No hypertriglyceridaemia occurred and plasma cholesterol levels fell. Simpson et al. (1979) suggest that it is no longer justifiable to prescribe a low-carbohydrate diet for 'maturity-onset' diabetes.

\section{Vascular disease}

Diabetic patients are approximately three times more predisposed to vascular disease than non-diabetics; the hyperlipidaemias and hyperinsulinaemia sometimes associated with diabetes may be partly responsible for this. It has been noted that a poor insulin response to oral glucose was associated with vascular complications in 117 mild diabetics studied by Elkeles et al. (1971), and it is interesting to note that a high-carbohydrate diet results in an enhanced early insulin response (Lerner et al. 1971). However, in some diabetics highcarbohydrate diets may cause hypertriglyceridaemia which may also be associated with the development of atherosclerosis. In diets for diabetics, as used in most centres now, a large proportion of energy comes from animal and dairy fats, whereas by contrast in the Far East where low-fat diets are used, vascular disease in diabetics is very much less prevalent. With respect to microvascular 
complications (the retinopathy, nephropathy and neuropathy) there is increasing evidence that good control decreases the likelihood of their development. Any dietary manoeuvre which improves control may therefore be regarded as beneficial.

\section{Dietary fibre}

It is appropriate here to return to dietary fibre (the plant polysaccharides and lignin not hydrolysed by the small intestinal enzymes of man). Miranda \& Horwitz (1978) studied the effect of increasing fibre intake without altering the proportion of energy derived from carbohydrate. Eight insulin-requiring diabetics were given a low-fibre diet ( $3 \mathrm{~g}$ crude fibre) and a high-fibre diet ( $20 \mathrm{~g}$ crude fibre) in random order; the total dietary fibre content of the diets would of course have been higher in both cases. Mean plasma glucose values were lower on the high-fibre diet. Jenkins et al. (1977) have shown that the addition of viscous types of dietary fibre (guar gum, a galactomannan storage polysaccharide and pectin, a polymer of galacturonic acid) to carbohydrate-containing meals reduced postprandial hyperglycaemia and insulinaemia in normal volunteers. They also showed a similar effect in diabetics (Jenkins et al. 1976). The same group has also reported that 14-26 g guar gum administered as a crispbread to nineteen diabetics (seven insulin-requiring) resulted in a significant reduction of urinary glucose loss during $5 \mathrm{~d}$ metabolic studies and that after 8 weeks' treatment insulin dosage and hometested glycosuria were reduced (Jenkins, Wolever, Nineham et al. 1978). It has been suggested that the property of these polysaccharides which is responsible for their effects is viscosity (Jenkins, Wolever, Leeds et al. 1978). Pectin slows gastric emptying in patients who have had gastric surgery and guar gum and pectin combined slow gastric emptying in normal volunteers (Holt et al. 1979). A slowing of gastric emptying and a delay in delivery of starch for hydrolysis seems likely to occur, but Jenkins, Wolever, Leeds et al. (1978) have suggested that a slowing of diffusion of glucose through the small intestinal contents also slows absorption. Meal viscosity may have other effects which could affect diabetic control. Giving large enough doses of a viscous type of fibre with a large dose of absorbable carbohydrate might result in carbohydrate malabsorption, but there is no evidence yet that viscous polysaccharides cause carbohydrate malabsorption. Faecal fats do increase when large enough doses of guar gum are given and this would effectively reduce the percentage of energy derived from fat. Guar gum also impairs the absorption of protein under certain experimental conditions. Other variables which might affect the true availability of nutrients might be the extent to which vegetable foods are crushed and cooked. Douglass (1975) has reported the effect of a 'raw' diet of uncooked vegetables, seeds, nuts and fruits and was able to reduce insulin doses. The long-term use of a high-fibre diet may result in changes of localized transport capacity for glucose in the small gut resulting in improved glucose tolerance.

\section{Summary}

The ultimate object of all types of dietary management before the introduction of insulin was to prevent emaciation and death: the consequences of metabolic 
derangements due to lack of insulin. Now, while dietary therapy continues to be important in minimizing the requirement for endogenous insulin or in balancing administered insulin, the major objects are changing to prevention of large vessel and microvascular disease. The next decade will probably see a more widespread introduction of diets containing a lower proportion of energy derived from fat. The increased carbohydrate intake will almost inevitably result in increased dietary fibre intake. Whether David Jenkins' Lente carbohydrate foods (those containing viscous unabsorbable polysaccharides) will prove to be of lasting value is not yet known. Since galactomannans occur in legumes perhaps we should consider the possibility of diets containing large proportions of legumes: a twentieth century 'Legume cure'? If this should prove of value it would not have excited ancient Indian physicians who wrote (in the Caraka-Samitã) of their use of legumes in the treatment of glycosuria, at least as early as the first century AD, before Aretaeus had applied the term diabetes.

The author is grateful for assistance given by staff of The Wellcome Institute for the History of Medicine and for helpful advice and criticism from Miss A. M. Brown.

\section{REFERENCES}

Anderson J. W. \& Chen, W. J. L. (1979). Am. Y. clin. Nutr. 32, 346.

Bierman, E. L., Albrink, M. J., Arky, R. A., Connor, W. E., Dayton, S. \& Spritz, N. (1971). Diabetes 20, 633 .

Cammidge, P. J. (1920a). Diabetic Dieting and Cooking, p. I6. London: University of London Press.

Cammidge, P. J. (1920h). Diabetic Dieting and Cooking, p. 62. London: University of London Press.

Cammidge, P. J. (1920c). Diabetic Dieting and Cooking, p. 142. London: University of London Press.

Douglass, J. M. (1975). Am. int. Med. 82, 61.

Elkeles, R. S., Lowy, C., Wyllie, A. D. H., Young, J. L. \& Russell Fraser, T. (1971). Lancet i, 880.

Graham, G. (1923). The Pathology and Treatment of Diabetes Mellitus, p. 99. London: Frowde and Hodder \& Stoughton.

Himsworth, H. P. (1934). Br. med. F. ii, 57.

Holt, S., Heading, R. C., Carter, D. C., Prescott, L. F. \& Tothill, P. (1979). Lancet i, 636.

Jenkins, D. J. A., Leeds, A. R., Gassull, M. A., Cochet, B. \& Alberti, K. G. M. M. (1977). Ann. int. Med. 86, 20

Jenkins, D. J. A., Leeds, A. R., Gassull, M. A., Wolever, T. M. S., Goff, D. V., Alberti, K. G. M. M. \& Hockaday, T. D. R. (1976). Lancet ii, 172 .

Jenkins, D. J. A., Wolever, T. M. S., Leeds, A. R., Gassull, M. A. Haisman, P., Dilawari, J., Goff, D. V., Metz, G. L. \& Alberti, K. G. M. M. (1978). Br. med. F. i, I 392.

Jenkins, D. J. A., Wolever, T. M. S., Leeds, A. R., Gassull, M. A., Haisman, P., Dilawari, J., Hockaday, T. D. R. (1978). Br. med. . ii, 1744 .

Kiehm, T. G., Anderson, J. W. \& Ward, K. (1976). Am. J. clin. Nut. 29, 895.

Lerner, R. L., Brunzell, J. D., Hazzard, W. R., Porte, D. \& Bierman, E. L. (1971). Diahetes 20, 342.

Maclean, H. (1927). Modern Methods in the Diagnosis and Treatment of Glycosuria and Diabetes, ch. 7. London: Constable.

Marwood, S. F. (1975). Hist. Med. 6, I8.

Miranda, P. M. \& Horwitz, D. L. (1978). Ann. int. Med. 88, 482.

Paul, A. A. \& Southgate, D. A. T. (1978). McCance and Widdowson's The Composition of Foods. London: H. M. Stationery Office.

Richardson, R. (1929). Am. F. med. Sci. 177, 426 . 
Rollo, J. (1797). An Account of Troo Cases of the Diabetes Mellitus, p. 173. London: Dilly.

Sansum, W. D., Blatherwick, N. R. \& Bowden, R., (1926). f. Am. med. Ass. 86, i78.

Simpson, R. W., Mann, J. I., Eaton, J., Moore, R. A., Carter, R. \& Hockaday, T. D. R. (1979). Bri. med. f. i, I753.

Truswell, A. S., Thomas, B. J. \& Brown, A. M. (1975). Br. med. J. iv, 7.

Walker, G. F. (1953). Lancet ii, 1329.

Weinsier, R. L., Seeman, A., Herrera, M. G., Assal, J. P. Soeldner, S. \& Gleason, R. E. (1974). Ann. int. Med. 80, $33^{2}$.

West, K. M. (1973). Ann. int. Med. 79, 425.

Willis, T. (1684). Practice of Physick: Pharmaceutice Rationalis, ch. 3, p. 76. London: Dring.

Wood, F. C. \& Bierman, E. L. (1972). Nutr. Today 7, 4. 